Revue d'histoire de l'Amérique française

RAS REVUE D.HISTOIRE DE L'AMÉRIQUE FRANÇAISE

\title{
La Querelle de l'eau-de-vie sous le régime-français (suite)
}

\section{Honorius Provost}

Volume 2, numéro 1, juin 1948

URI : https://id.erudit.org/iderudit/801444ar

DOI : https://doi.org/10.7202/801444ar

Aller au sommaire du numéro

Éditeur(s)

Institut d'histoire de l'Amérique française

ISSN

0035-2357 (imprimé)

1492-1383 (numérique)

Découvrir la revue

Citer ce document

Provost, H. (1948). La Querelle de l'eau-de-vie sous le régime-français (suite).

Revue d'histoire de l'Amérique française, 2(1), 138-140.

https://doi.org/10.7202/801444ar d'utilisation que vous pouvez consulter en ligne.

https://apropos.erudit.org/fr/usagers/politique-dutilisation/ 


\section{BIBLIOGRAPHIE}

\section{La Querelle de l'eau-de-vie sans le régime-francais (suite) ${ }^{1}$}

C) Archives du séminaire de Québec:

1647, le 19 juillet - Condamnation de Lafontaine pour traite des boissons (Doc. Faribault, 70).

1647, 12 et 13 sept. - Rapport de Jean Marsolet sur les désordres a Sillery (Doc. Faribault, 72, 73).

1659, 18 janv. - Règlement par Maisonneuve contre l'eau-de-vie (Saberdache Rouge, M. III, p. 87):

1660, 5 mars - Excommunication contre les traiteurs (Évêques, 171, p. 2).

1660-1669 - Extraits des registres du Conseil Souverain sur la question (Polygraphie IV, nos 22-26).

1662, 1 f'év. - Délibération de la Sorbonne (Évêques, 171, p. 2).

1662, 24 f'év. - Excommunication contre les traiteurs (Séminaire 15, no 6).

1666 - Extrait des lois de Boston touchant la traite (Polygraphie IV, no 21).

[1674] - Lettre de Mgr de Laval au Séminaire de Québec (Lettres S, no 39).

1674 - Les Hurons demandent de ne leur point donner d'eau-de-vie (Polygraphie IV, no 20).

1675, 8 mars - Réponse de la Sorbonne à un cas proposé (Polygraphie IV, no 27).

1675, 20 oct. - Assemblée des habitants de Montréal (Fonds Verreau, cahier D, p. 156).

1676, 9 sept. - Pitoin et Dupré condamnés pour avoir traité à la Baie St-Paul (Séminaire 28, no 7).

1677, 12 mai - Lettre de l'abbé Dudouyt (Lettres S, no 93).

1677 - Lettre du même à Mgr de Laval (Lettres N., no 48, 2o).

1678, 12 mai - Ordonnance du Roi à Frontenac pour une assemblée des citoyens (Polygraphie IV, no 28).

1- Nous sommes heureux de publier cette suite à la BIBLIOGRAPHIE parue dans la Revue d'Histoire de l'A mérique française, vol. I, no 4, mars 1948, p. 615-24. Nous devons ce supplément à l'un de nos membres-correspondants, M. l'abbé Honorius Provost, des Archives du Séminaire de Québec. 
1681, 10 mai - Réduction des droits sur les boissons en faveur des communaútés religieuses (Polygraphie VI, no 44).

1685 - Mgr de Laval défend les boissons aux sauvages du Sault (Séminaire $\mathrm{V}$, no 10 , p. 6 ).

1686, 31 mai - Instructions du Roi à Champigny (Polygraphie IV, 18).

1691, 3 sept. - Séminaire de Québec à celui de Paris (Lettres M, no 11, p. 3).

1695 - L'eau-de-vie à Michillimakinac (Saberdache rouge, N. III, p. 143).

[1696] - Instructions de Mgr de St-Vallier au sujet des marchands de boissons (Fonds Verreau, carton 13, no 40).

1701, 26 juillet - René Fournier condamné pour traite à Ste-Anne de Beaupré (Séminaire 20, no 7, p. 38).

1702, 30 aoû.t - Lettre du P. de Carheil à l'Intendant (Fonds Verreau, Boîte 17, $\mathrm{K}$ à L).

1703 - La traite jugée par Vaudreuil et Beauharnois (Saberdache rouge N. III, p. 26).

1706 - Permis de donner de l'eau-de-vie aux sauvages en des cas particuliers (Saberdache rouge, No IV, p. 29).

1712-1722 - Extraits de lettres du Ministre (Saberdache rouge, No IV, p. 126-127).

1719, 28 fév. - Condamnation de cinq vendeurs à Montréal (Fonds Verreau, Boîte 18, liasse IX, feuillet 17).

1726, 7 mai - Vente permise par le Conseil de Marine (Saberdache rouge, $\mathrm{N}$. IV, p. 175).

1726 - Mgr de St-Vallier au Conseil au sujet des boissons (Saberdache rouge No $I V$, p. 182).

1735, 5 janv. - Défense à Guilbault, de St-Joachim, d'en vendre (Séminaire 29 , no 32 ).

1737, 20 août - Duburon, vendeur au Détroit (Fonds Verreau, Carton 11 no 21).

1738 - Comment on fait la traite en Acadie (Lettres R, no 87).

1751, 20 mars - Permis à M. de St-Pierre d'en apporter pour son voyage à la mer de l'Ouest (Fonds Verreau, carton 5, no 29).

1756, 18 août - Lettre de Vaudreuil et Bigot à M. de Lavaltrie au sujet des boissons (Album Gaspé, no 258).

... - L'eau-de-vie dans la conclusion des marchés (Séminaire 8, nos 42 et 43.$)$

.... - Mémoire des arrêts, défenses de traiter des boissons aux sauvages (Polygraphie IV, no 19).

.... - Monographie sur la traite de l'eau-de-vie au Canada, par Mgr A.-E. Gosselin (cahier mans. 377).

D) Archives de L'archevêché de Québec:

N.B. Le Rapport de l'Archiviste de la Province de Québec, années 1939-40, 1940-41 et 1941-42, a publié un inventaire des documents pour l'histoire 
de l'Église du Canada sous le régime français, préparé par feu l'abbê Ivanhoë Caron; les documents concernant la traite de l'eau-de-vie conservés aux archives de l'Archevêché de Québec y ont été inventoriés, mais seulement jusqu'à l'année 1729, date où la mort de l'auteur a suspendu son travail; la liste ci-après servira de supplément jusqu'à 1760.

17. . - Gravés désordres surtout chez les sauvages; réfutation des prétextes invoqués (Lettres II, 373 à 383).

1730, 19 oct. - Québec. Les missionnaires attestent que l'eau-de-vie entrave la conversion des sauvages (Lettres II, p. 441).

1731, 17 avril - Versailles. Maurepas recommande à l'Évêque de réprimer les abus dans la traite (F. I, 19).

1732-1733 - Versailles. Le Roi trouve trop sévère le mandement contre la traite (F. I, 43, 50).

1733, 23 janv. - Paris. Au sujet du mandement de Mgr Dosquet faisant de la traite un cas réservé (Lettres II, 465: G. III, 93).

1742, 27 avril - Fontainebleau. Motifs de ne pas abolir la traite de l'eau-de-vie en Canada (F. I, 64).

1743, 21 mai - Versailles. Idées de Sa Majesté au sujet de la traite (F I, 71).

1750, 4 avril - Paris. Traite à contrôler mais non à supprimer en Louisiane; cas soumis par les Jésuites (V.G. III, 47, 51).

1752, 17 avril - Paris. La Cour est déterminée à soutenir la traite; intérêts de l'État vs ceux de la religion (V.G. III, 94).

1753, 1 avril - Paris. Sur les moyens de remédier aux désordres (V.G. III, 188, 189).

1756, 28 mars - Paris. Desordres de la traite dans les oolonies (V.G. IV, 158). 